\title{
A LEI 5.692 DE 1971 E A PRESENÇA DOS PRECEITOS LIBERAIS E ESCOLANOVISTAS: OS ESTUDOS SOCIAIS E A FORMAÇÃO DA CIDADANIA.
}

\section{RESUMO:}

Mara Regina Martins Jacomeli Faculdade de Educação da UNICAMP/SP mararmj@unicamp.br

O texto discute como a Lei 5.692 de 1971, elaborada na ditadura militar, abordou temáticas sociais do currículo para o ensino fundamental. A formação para a cidadania fez parte do projeto educacional dos militares para a "mansidão" e os Estudos Sociais representaram os conhecimentos para tanto. A escola foi usada para divulgar valores desejáveis e manter a sociedade "pacífica", apesar da retórica liberal que defendia as liberdades individuais. Para além dessa retórica, os "porões da ditadura" calavam quem não concordasse com as imposições do regime militar. A ênfase nos Estudos Sociais traduziram quais conhecimentos seriam ministrados nas escolas, cumprindo com um papel muito importante: quebrar as resistências sociais, via um currículo carregado de valores morais e éticos, pensados para a formação do cidadão no período.

Palavras-chave: História da Educação, Currículo, Cidadania, Ditadura Militar, Política Educacional

\section{THE 5692 LAW, OF 1971 AND THE PRESENCE OF LIBERAL and New School PRECEPTS: SOCIAL STUDIES AND THE FORMATION OF CITIZENSHIP.}

\begin{abstract}
:
The text discusses about how the 5692 Act of 1971, established during the military dictatorship, has addressed social themes of the curriculum for elementary schools. The training for citizenship education project was part of the military for "gentleness" and represented the social studies knowledge to do so. The school was used to promote desirable values and keep society peaceful "despite the liberal rhetoric that advocated individual liberties. Beyond this rhetoric, the "dungeons of dictatorship" shut up those who did not agree with the charges of the military regime. The emphasis in Social Studies which knowledge could be translated taught in schools, fulfilling an important role: to bring down social resistance, by a resume loaded with moral and ethical values, thought to the citizens training in the period.
\end{abstract}

Keywords: History of Education, Curriculum, Citizenship, Military Dictatorship, Education Policy

\section{Apresentação}

No texto ${ }^{1}$ discuto como a Lei 5.692/71 apresentou a abordagem de temáticas sociais através de seu currículo, caracterizando como tais temas se fizeram presentes na legislação educacional do período histórico da ditadura militar no Brasil. A intenção é evidenciar como os Estudos Sociais e, nele, a disciplina de Educação Moral e Cívica, não passaram de expressão de adequações do discurso liberal. A retórica liberal utilizou-se e utiliza-se da escola como forma de divulgar valores desejáveis para manter a sociedade "coesa" e "pacífica", de acordo com os preceitos postulados por sua ideologia. Isso pode ser percebido quando da análise dessa legislação e currículo para o nível de ensino fundamental no período. 
O que quero explicitar em meu texto é que a proposta dos Estudos Sociais e as temáticas sociais ali presentes representaram uma tentativa de reorganização do discurso liberal em educação, sendo uma adequação do que já foi discutido em outros tempos no âmbito das ideologias educacionais liberais, como exemplo, pelos escolanovistas. Algumas questões são certamente diferenciadas, já que também a sociedade da década de 1970 trazia características e exigências que não estavam presentes no seu passado, mas o "chão" teórico ainda era dado pelo liberalismo. Era o caso da visão e do discurso de transformação e adequação da sociedade pela reforma da escola e pela divulgação de valores desejáveis para o determinado momento histórico.

Nesse sentido, compactuo com a idéia de que no projeto de sociedade capitalista, o currículo escolar é um excelente meio para divulgar ideologias favoráveis à implementação da visão de mundo dominante. Em muitos momentos de crise pelos quais passa/passou o capitalismo, a educação é alçada à primeira instância de cuidado do Estado, numa tentativa de reordenamento desta mesma sociedade. Assim, no texto evidencio como a educação para a formação da cidadania fez parte do projeto educacional dos militares para a "mansidão" e os Estudos Sociais representaram os conhecimentos para tanto. A escola foi usada para divulgar valores desejáveis e manter a sociedade "pacífica", apesar da retórica liberal e escolanovista que defendia as liberdades individuais. Para além dessa retórica, os "porões da ditadura" calavam quem não concordasse com as imposições do regime militar. A ênfase nos Estudos Sociais traduziram quais conhecimentos seriam ministrados nas escolas, cumprindo com um papel muito importante, qual seja: quebrar as resistências sociais, via um currículo carregado de valores morais e éticos, pensados para a formação do cidadão.

\section{A contexto da reforma educacional}

Os discursos em torno da Lei 5.692/71, durante a ditadura militar brasileira, e que substituíram praticamente na íntegra a legislação educacional expressa pela primeira Lei de Diretrizes e Bases da Educação, a Lei 4.024/61, diziam que a necessidade de alteração da legislação atendia aos ditames de um "novo" momento social. Para tanto, esse momento pedia uma "nova" escola e uma "nova" visão educacional. Assim, a Lei 5.692/71 foi saudada como a panacéia, como a redenção da educação brasileira, ironicamente, até mesmo entre os educadores no período militar. A reforma educacional implantada atendia ao chamado de construção de um "projeto nacional" que serviria como alavanca para o desenvolvimento do "Brasil - Potência" (Saviani, 1987, p. 127).

A educação, no decorrer do período que vai de 1964 a 1985, relacionou-se à repressão, à privatização do ensino, à exclusão de grande parcela das classes populares do ensino público de boa qualidade, à institucionalização do ensino profissionalizante, à desmobilização do magistério pela via de uma legislação educacional complexa e contraditória e ao tecnicismo pedagógico.

Quanto ao modelo econômico que se instaurou com o golpe, não podemos dizer que ele representou uma mudança efetiva em relação aos anos anteriores, já que houve uma continuidade das políticas econômicas adotadas até então. Nos anos de 1950 a 1960, entretanto, foi se percebendo uma grande contradição: se por um lado a superestrutura ideológica respirava o clima do nacional-desenvolvimentismo, por outro lado, a política do governo não seguiu essa ideologia, optando, sim, pela abertura do Brasil aos investimentos do capital externo. A ideologia nacional-desenvolvimentista era defendida e divulgada por pesquisadores do Instituto Superior de Estudos Brasileiros (ISEB). Isso verificou-se nas décadas de 1950 e 1960, quando o crescimento do parque industrial brasileiro se deu a partir do capital monopolista estatal e multinacional, ao mesmo tempo em que se 
professava uma ideologia que defendia o desenvolvimento brasileiro pelo fortalecimento do capital nacional. As contradições econômicas e sociais advindas dessa política criaram um clima propício para o Golpe de 1964.

O Golpe acabou por combater a ideologia nacional-desenvolvimentista, substituindo-a pela ideologia da ESG (Escola Superior de Guerra) que pregava o "desenvolvimento com segurança" e facilitava a entrada do capital estrangeiro no país.

Com os militares no poder, verificou-se no Brasil uma política de repressão da sociedade civil e um controle estatal direto em escolas, sindicatos, partidos políticos e outros. Foi no período que um dos mecanismos mais ferozes de controle das liberdades dos cidadãos brasileiros, os Atos Institucionais, dentre eles, o AI - 5 de 1968, foram implementados. Não sem motivo, também a ditadura militar conviveu com a resistência da esquerda, muitas vezes armada que, de todas as maneiras, buscou reverter a situação política e social na qual estava submersa a sociedade brasileira.

Assim, a partir de tal contexto vimos nascer uma "nova" reforma educacional que alterava toda a estruturação do ensino brasileiro, bem como a que nos interessa no presente texto: a Lei 5.692/71.

E foi, no interior dos embates políticos, sociais e econômicos, que a educação foi reformada para forjar o "novo" cidadão, obediente e pacífico e que a ditadura militar almejava para a sociedade. Nessa reforma educacional, os Estudos Sociais, que englobavam as disciplinas de História e Geografia e a disciplina de Educação Moral e Cívica, teriam a função de "inculcar" os valores sociais desejáveis para o governo militar.

\section{A Lei 5.692/71 e os Estudos Sociais}

A Lei 5.692/71 fixou as diretrizes de implementação e implantação do ensino de $1^{\circ}$ e $2^{\circ}$ graus. Quanto ao objetivo geral, a legislação dizia:

Art. $1^{\circ}-\mathrm{O}$ ensino de $1^{\circ}$ e $2^{\circ}$ graus tem por objetivo geral proporcionar ao educando a formação necessária ao desenvolvimento de suas potencialidades como elemento de autorealização, qualificação para o trabalho e preparo para o exercício consciente da cidadania ${ }^{2}$.

$\S 1^{\circ}$ - Para efeito do que dispõem os Arts. 176 e 178 da Constituição, entende-se por ensino primário a educação correspondente ao ensino de primeiro grau e por ensino médio, o de segundo grau.

$\S 2^{\circ}-\mathrm{O}$ ensino de $1^{\circ}$ e $2^{\circ}$ graus será ministrado obrigatoriamente na língua nacional (Secretaria de Estado dos Negócios da Educação ...., 1976, p. 7).

$\mathrm{Na}$ orientação dada ao currículo, ao conhecimento ministrado nas escolas, a legislação apontou para a necessidade de um núcleo comum obrigatório para todo o Brasil e de uma parte diversificada que atendesse às especificidades locais, individuais etc..

Art. $4^{\circ}-$ Os currículos do ensino de $1^{\circ}$ e $2^{\circ}$ graus terão um núcleo comum, obrigatório em âmbito nacional, e uma parte diversificada para atender, conforme as necessidades e possibilidades concretas, às peculiaridades locais, aos planos dos estabelecimentos e às diferenças individuais dos alunos.

$\S 1^{\circ}$ - Observar-se-ão as seguintes prescrições na definição dos conteúdos curriculares: 
I - O Conselho Federal de Educação fixará para cada grau as matérias relativas ao núcleo comum, definindo-lhes os objetivos e amplitude.

II - Os Conselhos de Educação relacionarão, para os respectivos sistemas de ensino, as matérias dentre as quais poderá cada estabelecimento escolher as que devam constituir a parte diversificada.

III - Com aprovação do competente Conselho de Educação, o estabelecimento poderá incluir estudos não decorrentes de matérias relacionadas de acordo com o inciso anterior.

$\S 2^{\circ}$ - No ensino de $1^{\circ}$ e $2^{\circ}$ graus dar-se-á especial relevo ao estudo da língua nacional, como instrumento de comunicação e como expressão da cultura brasileira.

$\S 3^{\circ}$ - Para o ensino de $2^{\circ}$ grau o Conselho Federal de Educação fixará, além do núcleo comum, o mínimo a ser exigido em cada habilitação profissional ou conjunto de habilitações afins.

$\S 4^{\circ}$ - Mediante aprovação do Conselho Federal de Educação, os estabelecimentos de ensino poderão oferecer outras habilitações profissionais para as quais não haja mínimos de currículo previamente estabelecidos por aquele órgão, assegurada a validade nacional dos respectivos estudos (Secretaria de Estado dos Negócios da Educação ...., 1976, p. 8).

Para a organização do conhecimento, o documento prescreveu o trabalho pedagógico a partir da noção de disciplinas, áreas de estudo e atividades.

Art. $5^{\circ}$ - As disciplinas, áreas de estudo e atividades que resultem das matérias fixadas na forma do artigo anterior, com as disposições necessárias ao seu relacionamento, ordenação e seqüência, constituirão para cada grupo o currículo pleno do estabelecimento.

$\S 1^{\circ}$ - Observadas as normas de cada sistema de ensino, o currículo pleno terá uma parte de educação geral e outra de formação especial, sendo organizado de modo que:

a) no ensino de primeiro grau, a parte de educação geral seja exclusiva nas séries iniciais e predominante nas finais;

b) no ensino de segundo grau, predomine a parte de formação especial.

$\S 2^{\circ}$ - A parte de formação especial do currículo:

a) terá o objetivo de sondagem de aptidões e iniciação para o trabalho, no ensino de $1^{\circ}$ grau, e de habilitação profissional, no ensino de $2^{\circ}$ grau;

b) será fixada, quando se destine a iniciação e habilitação profissional em consonância com as necessidades do mercado de trabalho local ou regional, à vista de levantamentos periodicamente renovados.

$\S 3^{\circ}$ - Excepcionalmente, a parte especial do currículo poderá assumir no ensino de $2^{\circ}$ grau, o caráter de aprofundamento em determinada ordem de estudos gerais, para atender a aptidão 
específica do estudante, por indicação de professores e orientadores (Secretaria de Estado dos Negócios da Educação ...., 1976, p. 8).

A Lei determinou também que, no currículo pleno de todas as instituições escolares e de todos os graus, estivessem presentes a disciplina de Educação Moral e Cívica e a de Programas de Saúde, fazendo parte dos estudos para a formação do cidadão. O Parecer n ${ }^{\circ}$ 94/71, do Conselho Federal de Educação, intitulado Educação Moral e Cívica, apresenta a visão do que seria a educação moral e a cívica. Traz como relator, Dom Luciano José Cabral Duarte, arcebispo de Aracaju, o qual foi enfático quanto à visão conservadora, "de mãos dadas" com os preceitos morais postulados pela Igreja Católica. Da mesma maneira, a formação de um cidadão para viver numa democracia, no caso a brasileira, era um dos objetivos da disciplina.

Que visa, assim, a Educação Moral?

Visa a decantação do Instinto Moral de um ser livre, à sua formação consciente e crítica, ao seu aperfeiçoamento, no convívio com os outros, através do crescimento humano progressivo da criança, do adolescente e do jovem, até a idade adulta.

(...) A Educação Cívica visa, desta forma, basicamente, à formação da criança, do adolescente e do jovem para a Democracia. Entendendo-se a Democracia, à luz da Constituição do Brasil, como aquela forma de convivência social "cuja essência é evangélica" (no dizer de Bérgson), pois tem como fundamento a igualdade dos homens livres e como espírito o amor fraterno (Vasconcellos, 1972, p. 250 e 252).

Horta (1994) afirma que a Educação Moral e Cívica esteve presente nos currículos escolares, de forma explícita e às vezes implícita, em todas as formulações curriculares da educação de quase todos os níveis de ensino, ao longo de toda a história da república brasileira. Ela sempre teve a característica de ensino de valores, bem como a de "formar" os indivíduos, de acordo com a sociedade desejada.

De acordo com Cunha e Góes (1985, p. 76), a Educação Moral e Cívica implantada com a Lei 5.692/71 representou uma sólida fusão "do pensamento reacionário, do catolicismo conservador e da doutrina de segurança nacional". A importância da figura de Dom Luciano e sua influência nos encaminhamentos dados para a educação brasileira, foi destacada pelos autores.

Membro do Conselho Federal de Educação, o arcebispo Luciano já era o mais destacado intelectual da corrente integrista da Igreja Católica, que tem resistido às mudanças do Concílio Vaticano II e seus desdobramentos teológicos e pastorais. Como parte do acordo entre o setor reacionário da hierarquia da Igreja Católica e a ditadura, o arcebispo Luciano assumiu a presidência do Movimento de Educação de Base, demitindo toda a equipe técnica, na mesma época do parecer moral e cívico. Em seguida, atrelou o MEB ao Departamento de Ensino Supletivo do Ministério da Educação, transformando o mais importante sistema de educação de base jamais organizado no Brasil em mera linha auxiliar do Mobral, justamente quando este despontava como a grande solução para alcançar apoio das massas à ditadura (Cunha e Góes, 1985, p. 76). 
Assim, a Educação Moral e Cívica foi imposta como o necessário instrumento a ser implantado nas escolas para forjar as mentes e para incutir o espírito de patriotismo cultivado naquele momento político, onde deveria integrar a área de Estudos Sociais.

Segundo o Decreto-lei 869, de 1969, em seu Art. $2^{\circ}$, a Educação Moral e Cívica teria como finalidade:

a) a defesa do princípio democrático, através da preservação do espírito religioso, da dignidade da pessoa humana e do amor à liberdade com responsabilidade, sob a inspiração de Deus;

b) a preservação, o fortalecimento e a projeção dos valores espirituais e éticos da nacionalidade;

c) o fortalecimento da unidade nacional e do sentimento de solidariedade humana;

d) o culto à Pátria, aos seus símbolos, tradições, instituições, e aos grandes vultos de sua história;

e) o aprimoramento do caráter, com apoio na moral, na dedicação à família e à comunidade;

f) a compreensão dos direitos e deveres dos brasileiros e o conhecimento da organização sócio-político-econômica do País;

g) o preparo do cidadão para o exercício das atividades cívicas, com fundamento na moral, no patriotismo e na ação construtiva, visando ao bem comum;

h) o culto da obediência à Lei, da fidelidade ao trabalho e da integração na comunidade.

Parágrafo único. As bases filosóficas, de que trata este artigo, deverão motivar:

a) a ação nas respectivas disciplinas, de todos os titulares do magistério nacional, público ou privado, tendo em vista a formação da consciência cívica do aluno;

b) a prática educativa da moral e do civismo nos estabelecimentos de ensino, através de todas as atividades escolares, inclusive quanto ao desenvolvimento de hábitos democráticos, movimentos de juventude, estudos de problemas brasileiros, atos cívicos, promoções extra-classe e orientação dos pais (Secretaria de Estado dos Negócios da Educação ...., 1976, p. 135).

Chama a nossa atenção a postura nacionalista, patriótica, um verdadeiro culto ao militarismo, acobertado sob o princípio democrático, como se houvesse democracia em plena ditadura militar. Por trás do jargão de defesa de uma sociedade democrática se esconderam práticas de perseguição política, assassinatos e outras aberrações já enormemente analisadas e que estiveram escondidas nos "porões escuros" desse período.

Enfatizo que apenas alguns artigos da Lei 4.024/61 permaneceram em vigor e se somaram aos propostos pela 5.692/71. Justamente aqueles que tratavam dos fins da educação e que traziam um discurso com "cara" de democrático e com ênfase no respeito à liberdade individual, mesmo sendo tempos de perseguição política aos indivíduos que não concordavam com a ditadura militar. A liberdade foi/é uma das bandeiras do liberalismo e que a LDBEN/96 também professa, assim como professou a antiga LDB de 1961, bem como a Lei 5.692/71. Vejamos: 


\section{Título I}

Dos Fins da Educação

Art. $1^{\circ}$ - A educação nacional, inspirada nos princípios de liberdade e nos ideais de solidariedade humana, tem por fim:

a) a compreensão dos direitos e deveres da pessoa humana, do cidadão, do Estado, da família e dos demais grupos que compõem a comunidade;

b) o respeito à dignidade e às liberdades fundamentais do homem;

c) o fortalecimento da unidade nacional e da solidariedade internacional;

d) o desenvolvimento da personalidade humana e a sua participação na obra do bem comum;

e) o preparo do indivíduo e da sociedade para o domínio dos recursos científicos e tecnológicos que lhes permitam utilizar as possibilidades e vencer no meio;

f) a preservação do patrimônio cultural;

g) a condenação a qualquer tratamento desigual por motivo de convicção filosófica, política ou religiosa, bem como a quaisquer preconceitos de classe ou de raça (Secretaria de Estado dos Negócios da Educação ...., 1976, p. 17).

Este item evidencia bem que na lei, no papel, tudo é possível. Sabemos o que a ditadura militar fez para aqueles que não concordaram com o regime e que não comungaram com seus princípios. Portanto, o discurso de respeito às diferenças é bem mais antigo do que pensamos, mesmo que ele não tenha representado, realmente, respeito algum.

Quanto à questão ideológica, Fazenda (1988) afirma que as reformas educacionais ocorridas no período tiveram a herança da ideologia liberal, nacional-desenvolvimentista, forjada pelo ISEB. Após o golpe militar o ISEB é extinto e o Instituto de Pesquisa e Estudos Sociais (IPES) assume a sua função. O IPES já era uma instituição reacionária antes de ser a instituição de divulgação da ideologia militar, também liberal, que combatia as idéias das Reformas de Base, propostas pelas forças políticas de esquerda e, em certa medida, apoiadas por João Goulart (Jango). A distinção entre as duas vertentes liberais, do ISEB e do IPES, pode ser resumida da seguinte maneira: a primeira enfatizava o desenvolvimento do capitalismo brasileiro a partir do fortalecimento de parques industriais nacionais, mas era temida por ter aceitação até na esquerda política; a segunda defendia o desenvolvimento do Brasil, nos moldes capitalistas, a partir da união do capital nacional e externo, dela surgiu o jargão "desenvolvimento com segurança", expurgando a possibilidade de "ventos comunistas" baixarem por aqui.

Após a tomada do poder pelos militares, o Brasil "escancarou" as portas para o capital externo se instalar, prática essa que também esteve presente anteriormente em outros governos. Na verdade, com a instauração da República, o Brasil viveu muitos períodos de efervescência ideológica e teve governos como o de Vargas e o de Juscelino Kubitschek, por exemplo, que divulgavam uma ideologia liberal, nacionalista e desenvolvimentista, mas que não deixaram de atrelar o desenvolvimento econômico do país aos ditames e vontades do capital internacional, principalmente o americano, em função da ajuda financeira que este lhes proporcionava.

É interessante registrarmos como Fazenda (1988) evidencia o fato da ideologia liberal, travestida da perspectiva desenvolvimentista, estar presente nas falas dos relatores 
da reforma educacional, consubstanciada pela Lei 5.692/71. A sua presença na legislação representou um mecanismo, dentre outros, de sossegar vozes dissonantes no meio acadêmico e na sociedade de forma geral, cumprindo com um papel de "pacto do silêncio". Também a ideologia liberal se travestiu de um tecnicismo que estava na base da política estatal do governo militar.

Aparentando ser uma visão de mundo universal, justa e neutra em relação a todos os membros da sociedade, o governo militar pós-64 (legítimo representante da classe dominante) passa a fazer uso de uma linguagem científico-tecnocrática em educação, toda repleta de símbolos e metáforas (como se fora o representante mais fiel da classe dominada). "Técnicos de alto nível, gostam de escrever de forma tecnicamente atualizada quando legislam, e expressam uma lógica tão refinada que o senso comum já não consegue perceber os limites entre o que pode fazer e o que desejaria fazer (Lizete A. G. Arelaro - A descentralização na Lei 5.692/71: coerência ou contradição? Tese da FEUSP apud Fazenda, 1988, p. 82)".

No período de 68 - 72, em clima de "euforia econômica", a técnica do planejamento vai sendo utilizada em larga escala, procurando dar à política estatal tecnocrática um cunho científico, através de uma linguagem precisa e convincente.

Embora muitos dos liberais houvessem sido afastados da esfera política, ao lado de uma "ideologia do planejamento" (que procurava introduzir, de maneira explícita e programada, mecanismos de intervenção que pudessem fornecer ao sistema maior previsão e rentabilidade), o discurso dos documentos da Reforma Educacional encontra-se circunscrito por uma ideologia liberal que o dignifica e o torna praticamente inquestionável.

Nascida no IPES (anteriormente citado), essa ideologia expressa pelos famosos Grupos de Trabalhos foi construída não só pelo aparelho governamental, mas, com o reforço fora do Estado, através das posições expressas nas resoluções das reuniões interamericanas de educação (Fazenda, 1988, p. 82).

Outra importante fonte de informação que a autora nos dá corrobora com a afirmação da presença da ideologia liberal e seus ideais de democracia, liberdade e solidariedade humana, na Lei. Ela, a ideologia liberal, foi usada até nos documentos que antecederam a homologação da Lei 5.691/71. Isso está evidente e pode ser verificado através da "fala" de uma relatora, Nise Pires, do I Grupo de Trabalho, responsável pela elaboração das diretrizes para a Educação Fundamental que foi implementada no período. Mesmo em tempos de ditadura, o liberalismo buscou, enquanto ideologia, não se descurar de seus componentes básicos. Para isso, a educação escolar, de nível fundamental, manteve-se como aquela necessária para a formação dos trabalhadores. Bem ao gosto de Adam Smith - módica para pouco tempo. Também a educação fundamental era vista como motor do desenvolvimento econômico, visão defendida pelos adeptos da Teoria do Capital Humano. Em países onde as forças produtivas se encontram em processo de pouco desenvolvimento, a educação fundamental basta para formar os trabalhadores. Vejamos:

O Brasil insere-se no mundo democrático, e, tendo em vista o princípio de unidade nacional e os ideais de liberdade e 
solidariedade humana, dispõe-se a oferecer à sua população, em igualdade de oportunidades, uma educação fundamental.

Por outro lado, salienta que "a realização do curso médio confere um 'status' mais alto na escala social, ao qual todos aspiram ascender. A busca é mais de prestígio que de eficácia pela ação educativa, o que representa fatal desvirtuamento de fins.

A educação fundamental pretende formar crianças e adolescentes felizes e ajustados e oferecer-lhes condições e situações de experiência que lhes permitam sentir-se participantes na vida comunitária.

A educação fundamental é justificável, ainda, em termos econômicos, porque o preenchimento da mão-de-obra por elementos com adequada formação básica amplia a rentabilidade do trabalho e acelera o desenvolvimento" (Reforma do Ensino Primário e Médio, CRPE, 1970 apud Fazenda, 1988, p. 83 - 84).

Com relação ao $1^{\circ}$ grau, especificamente, no Capítulo II, art. 17, a Lei 5.692/71 afirma que tal ensino estaria voltado para a formação da criança e do pré-adolescente, "variando em conteúdo e métodos segundo as fases de desenvolvimento dos alunos (Secretaria de Estado dos Negócios da Educação ...., 1976, p. 9) ". O $1^{0}$ grau teria a duração de oito anos.

Um melhor entendimento de como foi pensado e como deveria ser implementado o currículo e a área de Estudos Sociais encontra-se presente no Parecer 853/71, aprovado em 12/11/1971. Um dos relatores, Valnir Chagas (1984), mostra o entendimento de como foi pensada e teorizada a 5.692/71. Vale enfatizar que ele integrou o Grupo de Trabalho que elaborou o anteprojeto da mesma Lei. No livro que trata sobre a tal legislação, ele se auto-intitula "herdeiro" das idéias de Anísio Teixeira (Cf. Chagas, 1984, p. 77).

No Parecer fica bem definido o que chamam de núcleo-comum para o currículo. Dele fazem parte as matérias de Comunicação e Expressão, de Estudos Sociais e de Ciências. Também estão incluídas as disciplinas de Educação Moral e Cívica, de Educação Física, de Educação Artística, de Programas de Saúde e de Ensino Religioso, facultativo. "Associadas a elas, o núcleo configura o conteúdo abaixo do qual se terá por incompleta qualquer formação de $1^{\circ}$ e $2^{\circ}$ graus..." (Secretaria de Estado dos Negócios da Educação ...., 1976, p. 28). Os conteúdos de cada matéria seriam: a) Língua Portuguesa, em Comunicação e Expressão; b) Geografia, História e Organização Social e Política do Brasil, em Estudos Sociais; e c) Matemática e Ciências Físicas e Biológicas, em Ciências. Para a integração dos diferentes conhecimentos no núcleo comum, o documento enfatizava que:

Mas um núcleo comum não há de ser encarado isoladamente (art. $2^{\circ}$ ), se em termos de currículo, como já proclamavam os educadores do século XVIII, "tudo está em tudo". A Língua Portuguesa não pode estar separada, enquanto forma de Comunicação e Expressão, de Educação Artística ou de um Desenho, que se lhe acrescentem, sob pena de inevitável empobrecimento. A Geografia, a História e a Organização Social e Política do Brasil adquirem tanto mais sentido e vigor quanto mais se interpenetram com vistas à integração do aluno ao meio próximo e remoto; e para isso muito hão de contribuir atividades como as de Educação Física, Educação Artística e Educação Cívica, em que a 
discrepância individualista numa sessão de Canto Orfeônico, numa competição desportiva ou num debate público, por exemplo, acarreta sanção natural e automática emergente das próprias situações criadas (Secretaria de Estado dos Negócios da Educação ...., 1976, p. 33).

Vale enfatizar que no documento já estava posta a questão da escola e de seu conteúdo curricular como espaço e ferramenta para incutir e formar valores sociais e morais no homem. A citação seguinte explicita a forma como o legislador pensava a função do conhecimento escolar a ser ministrado e de que maneira ele se relacionava entre as áreas do currículo.

A Língua Portuguesa, portanto, será encarada como o instrumento por excelência de comunicação no duplo sentido de transmissão e compreensão de idéias, fatos e sentimentos e sob a dupla forma oral e gráfica, o que vale dizer: leitura, escrita e comunicação oral. Nesta última encontra-se um dos elementos mais evidentes de conexão entre a Língua e os Estudos Sociais, encarados como um mecanismo de integração do educando ao meio. Também não se há de esquecer, neste particular, a importância cada vez maior que assume nos dias atuais a linguagem falada, ao impacto dos meios de comunicação "audiovisual", a ponto de que, se já não vivemos uma cultura predominantemente oral, pelo menos as duas tendem a equilibrar-se.

(...) Ao lado de sua função instrumental, o ensino da Língua Portuguesa há de revestir, como antes se assinalou, um indispensável sentido de "expressão da Cultura Brasileira". As situações criadas e os textos escolhidos para leitura, em articulação com as outras matérias, devem conduzir a uma compreensão e apreciação de nossa História, da nossa Literatura, da Civilização que vimos construindo e dos nossos valores mais típicos. Isto, evidentemente, não há de conduzir a exclusivismos estreitos. (...) Seja como for, é preciso não esquecer que "atrás de uma língua há um país, nesse país existem homens, e que se pretende é conduzir a eles" M. Laloum.

Já nos encontramos, assim, em pleno domínio dos Estudos Sociais, cujo objetivo é a integração espácio-temporal e social do educando em âmbitos gradativamente mais amplos. Os seus componentes básicos são a Geografia e a História, focalizando-se na primeira a Terra e os fenômenos naturais referidos à experiência humana e, na segunda, o desenrolar dessa experiência através dos tempos. $\mathrm{O}$ fulcro do ensino, a começar pelo "estudo do meio", estará no aquie-agora do mundo em que vivemos e particularmente, do Brasil e do seu desenvolvimento; (...). O legado de outras épocas e a experiência presente de outros povos, se de um lado devem levar à compreensão entre os indivíduos e as nações, têm que de outra parte contribuir para situar construtivamente o homem em "sua circunstância".

Para sublinhar esta última função, introduziu-se nos Estudos Sociais um terceiro ingrediente representado pela Organização 
Social e Política do Brasil. Vinculando-se diretamente a um dos três objetivos do ensino de $1^{\circ}$ e $2^{\circ}$ graus - o preparo ao "exercício consciente da cidadania" - para o OSPB e para o Civismo devem convergir, em maior ou menor escala, não apenas a Geografia e a História da Cultura Brasileira, nas suas manifestações mais dinâmicas, e do processo em marcha do desenvolvimento nacional . (...) (Secretaria de Estado dos Negócios da Educação ...., 1976, p. $34-35)$ (grifos nossos).

As interpretações feitas por Nagle (1973) deixam claro que as matérias e conhecimentos presentes nesse currículo tinham o objetivo de padronização da formação dos alunos, tendo como fim último a manutenção da unidade nacional do país e, assim, contribuir para a estabilidade social, refletindo um grande controle ideológico. Daí as matérias obrigatórias serem fixadas pelo Conselho Federal de Educação.

Algumas matérias têm por função a formação da criança e do préadolescente brasileiros - objetivo da escola de $1^{\mathrm{o}}$ grau. Homogeneizando-os, desempenham uma função mais ampla, a de promover a unidade nacional. Por meio de matérias dessa natureza, deve-se estabelecer um denominador comum de ideais e valores, de usos e costumes, de maneiras de sentir, pensar e expressar-se, importantes para a comunhão e a estabilidade sociais. Por essas razões, essa matérias serão obrigatórias e fixadas pelo órgão central, o Conselho Federal de Educação, formando o núcleo comum (Lei 5.692/71, Art. $4^{\circ}, \S 1^{\circ}$, inciso I) do currículo da escola de $1^{\circ}$ grau em todo o Brasil (Nagle, 1973, p. 52).

Diferentemente da parte comum do currículo, a diversificada seria elaborada pelos Conselhos de Educação de cada sistema de ensino, que tinham por função relacionar as matérias de ensino, bem como pelos estabelecimentos escolares, que deveriam planejar seus currículos, atendendo ao preceito do núcleo-comum. Deveriam, para tanto, escolher, dentre aquelas disciplinas relacionadas pelos Conselhos de Educação, as que melhor se adequassem aos seus planos. Pois, "Tal relação será tanto mais operativa quanto mais rica, flexível e aberta se apresente (Nagle, 1973, p. 28)”.

A legislação analisada afirmava que os conteúdos obrigatórios deveriam levar ao desenvolvimento de capacidades e de habilidades que contribuíssem para que o indivíduo apreendesse atitudes e capacidades "harmônicas e socialmente desejáveis". Tais capacidades poderiam ser resumidas em: observação, reflexão, criação, discriminação de valores, julgamento, comunicação, convívio, cooperação, decisão e ação. Curiosa foi a maneira como o legislador explicitou a questão, claro que de acordo com o momento político vivenciado, onde moldar mentes e vontades seria extremamente conveniente e necessário à ditadura militar. E o Parecer 853/71 escancara que a educação deve servir como instrumento para uma "vigorosa imunização mental". Vejamos o Parecer 853/71:

Numa comparação decerto imperfeita, mas bastante ilustrativa, diremos que no processo educativo tais conhecimentos, experiências e habilidades são para essas atitudes e capacidades o que, no processo nutritivo, os alimentos são para as proteínas, os hidratos de carbono, as vitaminas, etc., em que devem transformarse. $\mathrm{O}$ que a isso não conduz é eliminado no último caso; como na Educação é "esquecido", sob pena de perturbações eruditas. 
Poder-se-ia pensar que no caminho, vamos recuando no tempo e enveredando pela clássica distinção das funções "de conteúdo" e de "disciplina" que se atribuíam às matérias de estudo; ou que avançamos demais, preconizando um currículo de atitudes e capacidades. Nem uma coisa nem outra, mas um pouco de cada. Ninguém ignora que, na Pedagogia dos dias atuais, uma tendência neodiciplinalista cresce e ganha força ante a convicção, que se generaliza, de que só uma vigorosa imunização mental, "une tête bien faite", poderá armar o homem moderno contra as sutis agressões dos meios de comunicação que ameaçam escravizá-lo. Se daí não se há de chegar ao extremo de estruturar um currículo inteiramente à base de "traços mentais", sonho ainda muito remoto, cabe pelo menos definir e orientar positivamente esse epifenômeno que, bem ou mal, fatalmente emerge do processo educativo (Secretaria de Estado dos Negócios da Educação ...., 1976, p. 35).

Quanto à visão e à fundamentação teórica de como se processa o ensino e a aprendizagem, o Parecer 853/71 justificava que o escalonamento e a variação das matérias, distribuídas ao longo dos currículos do ensino de $1^{\circ}$ e $2^{\circ}$ graus e distinguidas entre atividades, áreas de estudo e disciplinas, relacionava-se com as deduções e contribuições da Psicologia Evolutiva e da Psicologia Genética de Piaget.

A velha marcha "do concreto para o abstrato" apresenta-se hoje na Psicologia Genética de Piaget, por exemplo - sob a forma tríplice de um período "sensório-motor", seguido de uma fase de "operações concretas" que leva, na adolescência, às "operações" formais "... móveis e reversíveis". Se em nenhum momento cogitamos de uma correspondência simétrica entre esses três períodos e aquela tríplice classificação curricular, também não deixamos de considerar o que deles já se fez evidência no dia-a-dia da vida escolar: a montagem a partir do concreto e do mais para o menos amplo, do genérico para o específico ou, na classificação sempre atual de Claparède, de "generalização inconsciente" para a "generalização consciente" (Secretaria de Estado dos Negócios da Educação ...., 1976, p. 38).

Segundo Nagle (1973), para além da presença piagetiana na elaboração curricular, há uma nítida influência das teorizações escolanovistas na proposta de estruturação do currículo, por áreas de estudo, atividades e disciplina, verificadas na Lei 5.692/71 e, paralelamente, no Parecer 853/71 que amparou a homologação de tal legislação educacional. Esse aspecto é importante para o presente texto, já que trabalhamos com a idéia de que não estavam vivenciando o "novo" na educação, no currículo, mas sim, readequações de entendimentos educacionais já apontados pelos nossos primeiros defensores da Escola Nova, como Anísio Teixeira e outros. A ideologia liberal e escolanovista também se fizeram presentes neste currículo, mesmo sendo ele idealizado para uma escola sob a organização de governos militares.

As atividades constituem a principal inovação no currículo. Nos termos do "Parecer n. 853/71", constituem a categoria curricular de campo mais amplo. As aprendizagens, agora "desenvolver-se-ão antes sobre experiências colhidas em situações concretas" - 
"vivências de situações e exercícios" - que se caracterizam pela ocasionalidade. Por essas razões, às atividades se associam o assistemático, o concreto, o amplo, bem como o próximo e o global. Essa foi a maneira pela qual o legislador procurou ajustar o currículo da escola de $1^{\circ}$ grau, especialmente nas suas séries iniciais, às conclusões da psicologia da criança. Não é difícil, também, concluir que por esse caminho se está procurando adotar algumas idéias da "Escola Nova" na elaboração do currículo (Nagle, 1973, p. 51).

Por fim, corroborando com essa discussão, Ghiraldelli Jr (1991) evidencia em suas análises as adaptações sofridas pela ideologia da Escola Nova, ao longo de sua história. No caso do período da ditadura militar, a adaptação escolanovista fez surgir a sua versão tecnicista.

Mas a Pedagogia Nova não se reciclou apenas no decorrer de sua divulgação e penetração fora de seu berço. Internamente, ou seja, em seu próprio leito natural, a Pedagogia Nova foi se transformando e se adaptando aos desenvolvimentos da sociedade capitalista. Pelas mãos dos próprios educadores liberais, a Pedagogia Nova foi deixando os velhos mestres e incorporando novos nomes, demonstrando grande capacidade de recomposição e de rearticulação no sentido de não perder os espaços conquistados na sua luta por hegemonia na arena das teorias educacionais. Assim, durante os anos 60 e, posteriormente na década de 70, os textos de Dewey, Kilpatrick e outros foram paulatinamente perdendo espaço para versões mais cientificistas e psicologizantes do escolanovismo, baseadas em Piaget, Brunner e outros. Também os textos de Anísio Teixeira, Lourenço Filho e outros foram substituídos pelas leituras dos divulgadores do piagetianismo, cujo maior expoente foi Lauro de Oliveira Lima. Todo esse movimento da Pedagogia Nova canalizou energias para o parto de uma outra tendência: a Pedagogia Tecnicista, que se tornou teoria educacional após o Golpe de 64.

Tanto a LDBEN de 1961 (Lei 4.024/61) como a LDBEN de 1971 (Lei 5.692/71) contiveram princípios escolanovistas. A primeira ligou-se aos princípios originais da Pedagogia Nova. A segunda cedeu espaço ao escolanovismo já nos moldes da Pedagogia Tecnicista (Ghiraldelli Jr., p. 127 - 128).

\section{Considerações finais}

Algumas ressalvas se fazem necessárias para as considerações finais. Ao dizer que a ideologia liberal e escolanovista esteve também presente nas formulações da Lei 5.692/71 estamos afirmando que, no processo de transformação da sociedade capitalista, a mesma ideologia vai se moldando, a partir de apropriações teóricas dos próprios educadores liberais que buscam respostas aos desafios e embates de seu tempo histórico. Assim, não afirmamos que a ideologia liberal é um modelo rígido e sem flexibilidade, pois, se fosse dessa maneira, ela não estaria alçada à visão representativa da mesma sociedade durante bons séculos e até hoje. 
Afirmo que está claro que muitas questões vivenciadas e defendidas no passado estão presentes nos debates atuais em torno da visão de qual conhecimento ensinar nas escolas. Não estou, com isso, tendo uma visão anacrônica da história da educação brasileira. Entendo que as "permanências" verificadas nas legislações anteriores e atuais se devem ao fato de que não poderia ser de outra forma, já que ainda vivemos sob a organização da sociedade capitalista que divulga a sua ideologia, agora, no século XXI, na versão "neoliberal". Nesse sentido, alguns princípios fundantes do liberalismo estão presentes, como estarão sempre presentes enquanto esta sociedade sobreviver. E sob o capitalismo, a escola ainda foi/é um bom espaço para divulgar e inculcar valores desejáveis, contribuindo para "pacificar" os homens.

A análise das aproximações dos Estudos Sociais com as propostas escolanovistas elucidou como o liberalismo sempre utilizou/utiliza a retórica salvacionista da sociedade por meio da escola. Em todos os momentos de crise do capitalismo, o discurso de transformação da escola como forma de mudar a sociedade foi acionado, revivendo o mito da escola redentora e salvadora da humanidade. É a adoção e a ênfase das políticas educacionais para o currículo, principalmente nas questões de quais conhecimentos devem ser veiculados em períodos de crises sociais agudas.

Enfatizo que na retórica liberal e escolanovista, as conquistas e o desenvolvimento da sociedade não se dão pelas transformações das formas de produzir, mas sim, pela promoção via escola. Nessa abordagem, a função da escola é de redistribuir os indivíduos, conforme o talento de cada um, não pelo privilégio de sangue ou outros, mas pela competência. A supervalorização do indivíduo escamoteia o fracasso, ou seja, as causas desse fracasso não são atribuídas às questões de classes sociais, mas, sim, à capacidade de "vencer" de cada um. O individualismo, um dos pilares da ideologia liberal, como já dito, é exaltado em qualquer período da sociedade capitalista: em tempos ditos democráticos e até em tempos de ditadura militar. Dominar teoricamente as rearticulações do liberalismo e suas investidas na formação humana, via escola, é fundamental ao educador que luta por uma educação "para além do capital".

\section{Referências Bibliográficas}

CHAGAS, V. O ensino de $1^{\circ}$ e $2^{\circ}$ graus: antes, agora e depois? São Paulo: Saraiva, 1984. CUNHA, L. A.; GOÉS, M. de. O golpe na educação. 5 ed. Rio de Janeiro: Zahar, 1985.

FAZENDA, I. C. A. Educação no Brasil anos 60: o pacto do silêncio. 2 ed. São Paulo: Edições Loyola, 1988.

GHIRALDELLI JR., P.. História da educação. São Paulo: Cortez, 1991.

HORTA, J. S. B.. O hino, o sermão e a ordem do dia: regime autoritário e a educação no Brasil (1930 - 1945). Rio de Janeiro: Editora UFRJ, 1994.

JACOMELI, M. R. M. Dos Estudos Sociais aos Temas Transversais: análise histórica das políticas educacionais brasileiras $(1971$ - 2000). Tese de doutorado. Faculdade de Educação da Unicamp, 2004.

PCNs e Temas Transversais: análise histórica das políticas educacionais brasileiras. Campinas: Editora Alínea, 2007.

NAGLE, J.. A Reforma e o ensino. São Paulo: EDART, 1973.

SAVIANI, D.. Política e educação no Brasil: o papel do Congresso Nacional na legislação do ensino. São Paulo: Cortez: Autores Associados, 1987.

SECRETARIA de Estado dos Negócios da Educação. Diretrizes e bases da educação nacional: documentos básicos para a implantação da reforma do ensino de $1^{\mathrm{O}}$ e $2^{\mathrm{O}}$ graus. São Paulo: Imprensa Oficial do Estado de São Paulo, 1976. 
VASCONCELLOS, P. José de. Legislação fundamental do ensino de $1^{O}$ e $2^{O}$ graus. São Paulo: LISA Livros Irradiantes S.A., 1972.

\footnotetext{
${ }^{1}$ As análises aqui presentes integram minha pesquisa de doutorado intitulada: Dos Estudos Sociais aos Temas Transversais: análise histórica das políticas educacionais brasileiras (1971 - 2000), defendida no Programa de Pós-graduação da Faculdade de Educação da Unicamp em 2004.

2 Não muito diferente do que diz, por exemplo, a LDBEN de 1996, quanto aos fins da educação. Portanto, princípios que são considerados universais e imutáveis sob o capitalismo.
}

Artigo recebido em: 16/11/10

Aprovado em: 30/11/10 